\title{
A Versatile Protocol to Quantify BCR-mediated Phosphorylation in Human and Murine B Cell Subpopulations
}

Jasper Rip, Rudi W. Hendriks ${ }^{\#, ~ * ~ a n d ~ O d i l i a ~ B . ~ J . ~ C o r n e t h ", ~ * ~}$

\author{
Department of Pulmonary Medicine, Erasmus MC Rotterdam, The Netherlands \\ *For correspondence: r.hendriks@erasmusmc.nl; o.corneth@erasmusmc.nl \\ "Contributed equally to this work
}

\begin{abstract}
[Abstract] Signal transduction is the process by which molecular signals are transmitted from the cell surface to its interior, resulting in functional changes inside the cell. B cell receptor (BCR) signaling is of crucial importance for B cells, as it regulates their differentiation, selection, survival, cellular activation and proliferation. Upon BCR engagement by antigen several protein kinases, lipases and linker molecules become phosphorylated. Phosphoflow cytometry (phosphoflow) is a flow cytometry-based method allowing for analysis of protein phosphorylation in single cells. Due to recent advances in methodology and antibody availability - together with the relatively easy quantification of phosphorylation - phosphoflow is increasingly and more commonly used, compared to classical western blot analysis. It can however be challenging to set-up a method that works for all targets of interest. Here, we present a step-by-step phosphoflow protocol allowing the evaluation of the phosphorylation status of signaling molecules in conjunction with extensive staining to identify various human and murine B cell subpopulations, as was previously published in the original paper by Rip et al. (2020). Next to a description of phosphoflow targets from the original paper, we provide directions on additional targets that play a pivotal role in BCR signaling. The step-by-step phosphoflow protocol is user-friendly and provides sensitive detection of phosphorylation of various BCR signaling molecules in human and murine B cell subpopulations.
\end{abstract}

Keywords: Phosphoflow cytometry, Signal transduction, B cell receptor signaling, B cell subpopulations

[Background] B cells are a crucial part of the adaptive immune system and play an important role in protection against pathogens. B cells can sense pathogens by innate receptors such as Toll-like receptors (TLRs). The most important receptor for the development and activation of $B$ cells, however, is the $\mathrm{B}$-cell antigen receptor (BCR). The genes encoding the immunoglobulin heavy and light chains that comprise the BCR are assembled during $B$ cell development in the bone marrow through a stepwise process called V(D)J recombination (Tonegawa, 1983). The functionality and autoreactivity of the BCR are checked during three crucial checkpoints in B cell development: (i) productive heavy chain rearrangement is monitored at the pre-B stage by surface deposition of the heavy chain protein together with pre-existing surrogate light chain as the pre-BCR complex; (ii) productive light chain recombination enables surface expression of the BCR, which is checked for auto-reactivity at the immature B cell stage and (iii) upon bone marrow egress when transitional $B$ cell progress to mature, naive $B$ cells in peripheral lymphoid tissues. When expression of (pre-)BCR signaling molecules is altered, B cell development in 
the bone marrow is severely affected (Martensson et al., 2010; Pieper et al., 2013). Balanced BCR signaling is also crucial for appropriate selection, survival and activation of mature B cells and its distortion is a key factor in the development of autoimmune disease or leukemia (Nishizumi et al., 1995; Kil et al., 2012; Rip et al., 2018).

Upon BCR engagement by antigen, Src family kinases phosphorylate the intracellular tyrosine-based activation motif (ITAM) of CD79a (Ig- $\alpha)$ and CD79b (Ig- $\beta)$, which are the transmembrane proteins that form a complex with the BCR, as well the cytoplasmic tail of co-receptor CD19. Phosphorylation of the CD79a/b ITAM in turn activates spleen tyrosine kinase (SYK), which subsequently activates the SH2 domain-containing leukocyte protein of $65 \mathrm{kDa}$ (SLP-65) linker protein. Simultaneously, phosphorylated CD19 will activate phosphoinositide 3-kinase (PI3K), which in turn phosphorylates and converts phosphatidylinositol $(4,5)$-bisphosphate $\left(\mathrm{PIP}_{2}\right)$ to phosphatidylinositol $(3,4,5)$-triphosphate ( $\left.\mathrm{PIP}_{3}\right)$. Signaling molecules containing a pleckstrin-homology domain, such as Bruton's tyrosine kinase (BTK) and phospholipase CY2 (PLCY2), are recruited to the cell membrane by the newly formed $\mathrm{PIP}_{3}$ (Saito et al., 2001). After BTK recruitment to the cell membrane, SLP-65 mediates SYK-dependent activation of BTK, which in turn will phosphorylate PLCY2 (Wang et al., 2000). The activation of this signaling complex eventually results in activation of protein kinase B (PKB/AKT) signaling (Craxton et al., 1999), NF-KB translocation to the cell nucleus (Bajpai et al., 2000), calcium mobilization (Fluckiger et al., 1998) and activation of the mitogen-activated protein kinase (MAPK) pathway (Jiang et al., 1998). The complex containing BTK, SLP-65, PLCY2 together with other PI3K-derived signals is essential for B cell survival, proliferation and differentiation. BCR signal transduction is regulated by the equilibrium of kinase activity and negative regulation of signaling through recruitment of tyrosine phosphatases including SHP-1 (Franks and Cambier, 2018).

Western blotting used to be the method of choice for detection and quantification of phosphorylation of the BCR signaling molecules described above. The main drawbacks of Western blotting are the large number of purified cells that are required to perform the analysis and that quantification is not sensitive enough to detect subtle differences between samples. Phosphoflow is a flow-cytometry based technique that allows for quantification of multiple subpopulations within a single sample without prior purification and requires relatively few cells. In addition, phosphoflow cytometry is less time-consuming compared to Western blotting. Although for the quantification of protein phosphorylation phosphoflow appeared to be superior to Western blotting, the fixation and permeabilization procedure of phosphoflow often affected cellar epitopes or features of the monoclonal antibodies (mAbs) that were required to identify the immune cell population of interest. Due to recent advances in phosphoflow procedures, it is now possible to combine the analysis of phosphorylation of signaling proteins with a comprehensive staining for $B$ cell subpopulations. In addition, more and more mAbs become available for phosphoflow analysis.

Here, we present our step-by-step phosphoflow protocol that is complementary to our original research paper (Rip et al., 2020). The phosphoflow protocol allows for sensitive detection of phosphorylation of numerous BCR signaling molecules in human and murine B cell subpopulations. Next to a description of phosphoflow targets as published in the original paper (Rip et al., 2020), we also 
present additional BCR signaling targets that can be sensitively quantified using this phosphoflow protocol.

\section{Materials and Reagents}

\section{Acquisition of human PBMCs from whole blood}

1. Leucosep Tube, $50 \mathrm{ml}$ (Greiner Bio-One, catalog number: 227290)

2. $2 \mathrm{ml}$ Cryovial (Starstedt, catalog number: 72.694.006)

3. Total peripheral blood ( $25 \mathrm{ml})$ from a healthy donor or patient. In general, $1 \mathrm{ml}$ of blood contains $1 \times 10^{6}$ PBMCs.

4. Ficoll-Paque ${ }^{\mathrm{TM}}$ Plus (GE Healthcare, catalog number: 17-1440-03)

5. Fetal bovine serum (FBS, Gibco, catalog number: 10270-106)

CRITICAL: Heat-inactivate for $1 \mathrm{~h}$ at $56{ }^{\circ} \mathrm{C}$ prior to use.

6. $20 \%$ dimethyl sulfoxide (DMSO, Sigma-Aldrich, catalog number: D2650-100ML)

CAUTION: DMSO is a toxic product and should be handled with care and discarded.

7. RPMI 1640 Medium containing L-glutamine (Lonza, catalog number: BE12-702F) supplemented with 5\% (vol/vol) fetal bovine serum (Gibco, catalog number: 10270-106) (see Recipes)

8. Freezing medium containing $80 \%$ FBS (Gibco, catalog number: 10270-106) (see Recipes)

\section{Collection of Murine organs}

1. $10 \mathrm{ml}$ syringes (Braun, catalog number: $4616103 \mathrm{~V}$ ) and 25 -gauge $\times 5 / 8$ inch needle (Braun, catalog number: 4657853)

2. C57BL/6J mice (Charles River) that are 8-12 weeks of age, either males and females Note: All animal experiments should comply with national laws and institutional regulations.

3. PBS (Gibco, catalog number: 14190169)

\section{Preparation of Murine organs}

1. $100 \mu \mathrm{m}$ nylon strainers (Corning, catalog number: 352360 )

2. $2 \mathrm{ml}$ syringes (BD Biosciences, catalog number: 307727 )

3. Nunc Cell Culture/Petri dishes (Thermo Scientific, catalog number: 1533066)

4. RPMI 1640 Medium, Glutamax ${ }^{\mathrm{TM}}$ Supplement (Gibco, catalog number: 61870036) containing $2 \%$ (vol/vol) FBS (Capricorn, catalog number: FBS-12A) (see Recipes)

CRITICAL: Heat-inactivate for $1 \mathrm{~h}$ at $56^{\circ} \mathrm{C}$ prior to use.

In vitro Stimulation of Single-Cell Suspension/Direct fixation for ex vivo (basal) measurements

1. 96-wells plate (U-shaped, $310 \mu \mathrm{l} / \mathrm{w}$, Greiner Bio-One, catalog number: 650201)

2. eBioscience FoxP3/Transcription Factor staining kit (Invitrogen, catalog number: 00-5523-00) 
containing:

a. Fixation and permeabilization concentrate

CAUTION: This product contains paraformaldehyde (PFA), a toxic and mutagenic product.

It should be handled with care and discarded as hazardous waste.

b. Diluent

c. $10 \times$ Wash Buffer (dilute 10 times in deionized water)

3. Stimuli for BCR signaling and co-receptor engagement, see Table 1.

CAUTION: Sodium azide is highly toxic and dangerous to the environment. It should be handled with care and discarded as hazardous waste.

Table 1. BCR and co-receptor ligands for stimulation of human and murine B cells

\begin{tabular}{|c|c|c|c|}
\hline Stimulus & $\begin{array}{l}\text { Working } \\
\text { Concentration }\end{array}$ & Manufacturer & Cat. No. \\
\hline \multicolumn{4}{|l|}{ Human } \\
\hline Goat $F\left(a b^{\prime}\right)_{2}$ Anti-Human lgM-UNLB & $20 \mu \mathrm{g} / \mathrm{ml}$ & Southern Biotech & 2022-01 \\
\hline Recombinant Human CD40L & $2 \mu \mathrm{g} / \mathrm{ml}$ & $R \& D$ & 6245-CL/CF \\
\hline Recombinant Human IL-4 protein & $250 \mathrm{ng} / \mathrm{ml}$ & R\&D & 204-IL-CF \\
\hline \multicolumn{4}{|l|}{ Mouse } \\
\hline $\begin{array}{l}\text { AffiniPure } F\left(a b^{\prime}\right)_{2} \text { Fragment Goat Anti- } \\
\text { Mouse IgM }\end{array}$ & $25 \mu \mathrm{g} / \mathrm{ml}$ & $\begin{array}{l}\text { Jackson } \\
\text { ImmunoResearch }\end{array}$ & $115-006-075$ \\
\hline $\begin{array}{l}\text { Purified Rat anti-Mouse CD40 (clone } \\
3 / 23 \text { ) }\end{array}$ & $4 \mu \mathrm{g} / \mathrm{ml}$ & BD Biosciences & 553787 \\
\hline $\begin{array}{l}\text { Lipopolysaccharide (LPS) E. coli } \\
\text { 026:B6 }\end{array}$ & $400 \mathrm{ng} / \mathrm{ml}$ & Sigma-Aldrich & L8274 \\
\hline
\end{tabular}

\section{Flow Cytometry Procedures}

1. Insert tubes (Greiner Bio-One, catalog number: 102280) and $5 \mathrm{ml}$ round bottom polystyrene tubes (Corning, catalog number: 352052)

2. UltraComp eBeads ${ }^{\mathrm{TM}}$ Compensation Beads (Invitrogen, catalog number: 01-2222-42)

3. 10× Wash Buffer (dilute 10 times in deionized water) from the eBioscience FoxP3/Transcription Factor staining kit (Invitrogen)

4. FcR Blocking agent (Human TruStain FcX, Biolegend, catalog number: 422302)

5. Antibodies for flow cytometry are listed in Table 2 (phospho-protein-specific antibodies) and Table 3 (antibodies used for an accurate identification of B cell subpopulations). For mouse studies, another 2.4G2 antibody was used from own production.

CAUTION: Sodium azide is highly toxic (see above).

6. MACS-buffer containing $0.5 \%$ (vol/vol) bovine serum albumin (BSA, Sigma-Aldrich, catalog number: A8327) and $2 \mathrm{mM}$ ethylenediaminetetraacetic acid solution (EDTA, Sigma-Aldrich, catalog number: 03690) in PBS (see Recipes) 
Table 2. Phospho-specific antibodies for the analysis of human and mouse B cells and directions on stimulation timing and antibody dilution

\begin{tabular}{|c|c|c|c|c|c|c|c|c|}
\hline Antibody & Conjugate & Clone & Manufacturer & Cat. No. & $\begin{array}{l}\text { Detection } \\
\text { human }\end{array}$ & $\begin{array}{l}\text { mAb } \\
\text { Dilution } \\
\text { human }\end{array}$ & $\begin{array}{l}\text { Detection } \\
\text { mouse }\end{array}$ & $\begin{array}{l}\text { mAb } \\
\text { Dilution } \\
\text { mouse }\end{array}$ \\
\hline $\begin{array}{l}\text { pAKT } \\
\text { (S473) }\end{array}$ & - & D9E & $\begin{array}{l}\text { Cell Signaling } \\
\text { Technologies }\end{array}$ & $4060 \mathrm{~L}$ & $30-60 \min$ & $100 x$ & $180 \min$ & $100 x$ \\
\hline $\begin{array}{l}\text { pAKT } \\
(\mathrm{T} 308)\end{array}$ & - & D25E6 & $\begin{array}{l}\text { Cell Signaling } \\
\text { Technologies }\end{array}$ & 13038L & $30-60 \mathrm{~min}$ & $50 x$ & $180 \min$ & $100 x$ \\
\hline $\begin{array}{l}\text { pBTK/pITK } \\
\text { (Y223/Y180) }\end{array}$ & $\begin{array}{l}\text { Alexa } \\
\text { Fluor } 647\end{array}$ & N35-86 & BD phosflow & 564846 & $5 \mathrm{~min}$ & $3000 x$ & $5 \mathrm{~min}$ & $3000 x$ \\
\hline $\begin{array}{l}\text { pCD79a } \\
\text { (Y182) }\end{array}$ & $\begin{array}{l}\text { Alexa } \\
\text { Fluor } 647\end{array}$ & D1B9 & $\begin{array}{l}\text { Cell Signaling } \\
\text { Technologies }\end{array}$ & $29742 S$ & $1 \mathrm{~min}$ & $50 x$ & $5 \mathrm{~min}$ & $50 x$ \\
\hline $\begin{array}{l}\text { pERK1/2 } \\
(\text { T202/Y204) }\end{array}$ & PE & $20 \mathrm{~A}$ & BD phosflow & 561991 & $5 \mathrm{~min}$ & $8 x$ & $5 \mathrm{~min}$ & $8 x$ \\
\hline $\begin{array}{l}\text { pPI3K p85 } \\
(Y 458)\end{array}$ & - & E3UI1H & $\begin{array}{l}\text { Cell Signaling } \\
\text { Technologies }\end{array}$ & 17366S & $1 \mathrm{~min}$ & $100 x$ & $3 \min$ & $200 x$ \\
\hline $\begin{array}{l}\text { pPLCy2 } \\
(Y 759)\end{array}$ & $\begin{array}{l}\text { Alexa } \\
\text { Fluor } 647\end{array}$ & K86-689.37 & BD phosflow & 558498 & $5 \mathrm{~min}$ & $8 x$ & $5 \mathrm{~min}$ & $8 x$ \\
\hline $\begin{array}{l}\text { pS6 } \\
(\mathrm{S} 240 / 244)\end{array}$ & - & D68F8 & $\begin{array}{l}\text { Cell Signaling } \\
\text { Technologies }\end{array}$ & 5364 & $30-60 \mathrm{~min}$ & $200 x$ & $180 \mathrm{~min}$ & $200 x$ \\
\hline $\begin{array}{l}\text { pSHP-1 } \\
(\mathrm{Y} 564)\end{array}$ & - & D11G5 & $\begin{array}{l}\text { Cell Signaling } \\
\text { Technologies }\end{array}$ & 88495 & $1 \mathrm{~min}$ & $100 x$ & $3 \mathrm{~min}$ & $500 x$ \\
\hline $\begin{array}{l}\text { pSLP-65 } \\
\text { (Y84) }\end{array}$ & PE & J117-1278 & BD phosflow & 558442 & $2 \min$ & $8 x$ & $5 \mathrm{~min}$ & $8 x$ \\
\hline $\begin{array}{l}\mathrm{pSrc} \\
(\mathrm{Y} 418 / \mathrm{Y} 424)\end{array}$ & - & EP503Y & Abcam & Ab40660 & $1-3 \min$ & $200 x$ & $5 \mathrm{~min}$ & $500 x$ \\
\hline pSrc (Y507) & - & $5 B 6$ & Abwiz Bio & $2461 S$ & $1-3 \min$ & $500 x$ & $5 \mathrm{~min}$ & $1500 x$ \\
\hline pSYK (348) & PE & $\mid 120-722$ & BD phosflow & 558529 & $2 \min$ & $8 x$ & $5 \mathrm{~min}$ & $8 x$ \\
\hline
\end{tabular}


Table 3. Antibodies used for accurate gating of $B$ cell subsets

\begin{tabular}{llllll}
\hline Antibody & Conjugate & Clone & Manufacturer & Cat. No. & mAb dilution \\
\hline Human & & & & & \\
CD3 & Alexa Fluor 700 & UCHT1 & Invitrogen & $56-0038-42$ & $200 x$ \\
\hline CD19 & FITC & HIB19 & BD Biosciences & 555412 & $15 x$ \\
\hline CD27 & BV421 & M-T271 & BD Biosciences & 562513 & $10 x$ \\
\hline CD38 & BV785 & HIT2 & Biolegend & 303530 & $15 x$ \\
\hline IgD & BV605 & IA6-2 & BD Biosciences & 563313 & $400 x$ \\
\hline Mouse & & & & & \\
\hline B220 & AF700 & RA3-6B2 & Invitrogen & $56-0452-82$ & $200 x$ \\
\hline CD21 / CD35 & FITC & eBio4E3 & Invitrogen & $11-0212-85$ & $100 x$ \\
\hline CD23 & Biotin & B3B4 & BD Biosciences & 553137 & $400 x$ \\
\hline CD3 & BV421 & 145-2C11 & BD Bioscience & 562600 & $400 x$ \\
\hline IgD & BV711 & 11-26c.2a & BD Biosciences & 564275 & $2000 x$ \\
\hline IgM & PE-Cy7 & II/41 & BD Biosciences & $25-5790-82$ & $400 x$ \\
\hline Human and mouse & & & & & \\
\hline Fixable Viability & eFluor 506 & n.a. & Invitrogen & $65-0866-14$ & $200 x$ \\
Dye & & & & & $200 x$ \\
\hline Streptavidin & APC-eFluor & n.a. & Invitrogen & $47-4317-82$ & $200 x$ \\
\hline Streptavidin & BV78 & & & & \\
\hline
\end{tabular}

\section{Equipment}

1. Standard laboratory materials or equipment, such as pipettes, tubes, and tips

2. Tools suitable for sacrificing mice and harvesting organs, including: scissors, tweezers and $70 \%$ ethanol

3. Mortar and pestle

4. Stopwatch or timer

5. Water bath incubator and/or $\mathrm{CO}_{2}$ incubator

6. Multifuge $\times 3 R$ Refrigerated Centrifuge (Thermo Scientific, catalog number: 75004515) with TX1000 swinging bucket rotor (Thermo Scientific, catalog number: 75003017).

7. LSR II flow cytometer (BD Biosciences, catalog number: BD LSR-II) equipped with a red, blue and violet laser

8. Flow cabinet

9. $4{ }^{\circ} \mathrm{C}$ fridge

10. $-80^{\circ} \mathrm{C}$ freezer

\section{Software}

1. Data acquisition by FACSDiva ${ }^{\mathrm{TM}}$ Software (BD Biosciences) 
2. FlowJo software (BD Biosciences) to analyze data

\section{Procedure}

A. Sample collection

\section{Acquisition of human PBMCs from whole blood (Timing: 60 min)}

Note: Steps 1 to 6 are performed in a sterile environment using a flow cabinet.

1. Add $15 \mathrm{ml}$ of Ficoll to the Leucosep tube and spin down at $1,000 \times g$ for $1 \mathrm{~min}$ at room temperature (RT).

2. Gently load a maximum of $25 \mathrm{ml}$ whole blood per Leucosep tube.

CRITICAL: Make sure the Ficoll is beneath the filter in the tube and that blood does not mix with the Ficoll.

3. Spin down the Leucosep tube containing whole blood and Ficoll at 1,000 $\times g$ for 10 min at RT. CRITICAL: Set the deceleration as low as possible to keep the Ficoll gradient separation of the PBMC layer intact.

4. Transfer the whole solution of peripheral blood mononuclear cells (PBMCs), Ficoll and Plasma to a $50 \mathrm{ml}$ tube containing $15 \mathrm{ml}$ RPMI 1640 supplemented with 5\% FBS.

CRITICAL: The erythrocyte fraction below the filter should be retained in the Leucosep tube.

5. Spin down the $50 \mathrm{ml}$ tube at $400 \times g$ for $7 \mathrm{~min}$ at $4{ }^{\circ} \mathrm{C}$. Afterwards, remove the supernatant and resuspend in $1-5 \mathrm{ml}$ of cold $\left(4{ }^{\circ} \mathrm{C}\right) \mathrm{RPMI}-2 \%$ FBS.

OPTIONAL: When performing phosphoflow on fresh PBMCs (non-frozen samples), proceed to Step 9.

6. Count cells using standard procedures (manual or automated) and store not more than $50 \times 10^{6}$ viable cells per vial by adding Freezing medium in 1:1 ratio to the volume in which the cells are held. Add $0.5 \mathrm{ml}$ of Freezing medium to $0.5 \mathrm{ml}$ of medium containing $20 \times 10^{6}-50 \times 10^{6}$ cells. Transfer the cells into $2 \mathrm{ml}$ cryovials that are suitable for freezing and immediately freeze the vials at a rate of $1^{\circ} \mathrm{C}$ per minute.

CRITICAL: As DMSO is harmful to cells, slowly add the freezing medium to the cells in RMPI $5 \%$ FBS while gently shaking the tube.

PAUSE POINT: Cells can be kept at $-80{ }^{\circ} \mathrm{C}$ for several weeks or in liquid nitrogen for years. CAUTION: DMSO is a toxic product and should be handled with care and discarded.

7. Vials containing frozen PBMCs are thawed using a $37^{\circ} \mathrm{C}$ water bath. Upon reaching the liquid phase, cells are immediately transferred into a $15 \mathrm{ml}$ tube followed by slow addition $10 \mathrm{ml}$ of cold $\left(4{ }^{\circ} \mathrm{C}\right)$ RPMI-5\% FBS while gently shaking the tube.

CRITICAL: This transfer should happen immediately when the liquid phase is reached during thawing, as DMSO is harmful to the cells.

8. Spin down at $400 \times g$ for 7 min at $4{ }^{\circ} \mathrm{C}$. Afterwards, remove the supernatant and resuspend the pellet in $1 \mathrm{ml}$ of cold $\left(4^{\circ} \mathrm{C}\right)$ RPMI $2 \%$ FBS.

9. Count the cells and plate $5 \times 10^{5}$ cells per well in a 96-wells round bottom plate within a volume of $50 \mu \mathrm{LPMI} 2 \%$ FBS for phosphoflow. 
PAUSE POINT: Cells can be kept at $4{ }^{\circ} \mathrm{C}$ for $1-2 \mathrm{~h}$ before proceeding with the phosphoflow protocol at Step B1.

\section{Collection of murine organs (Timing: 15 min per mouse)}

1. Mice are sacrificed by cervical dislocation. The protocol allows for other sacrifice methods that do not affect the anatomical region of the organ of interest, including methods that involve anesthetics.

2. Peritoneal lavage. A midline incision over the abdomen is made to retract the skin, keeping the abdomen intact. A $10 \mathrm{ml}$ syringe, containing $5 \mathrm{ml}$ of ice-cold PBS and $5 \mathrm{ml}$ of air, is attached to the 25 -gauge $\times 5 / 8$ inch needle. The peritoneum is subsequently washed by gently flushing and shaking upon full injection for $1 \mathrm{~min}$. Afterwards, the peritoneal lavage is collected by aspirating the peritoneal cavity with the $10 \mathrm{ml}$ syringe. The lavage is collected in a $15 \mathrm{ml}$ tube and is kept on ice for further processing.

3. Spleen. The peritoneal cavity can be opened to carefully extract the spleen. The spleen is located at the left flank in the abdomen and can be extracted using tweezers.

4. Other organs. Next, the Peyer's patches can be isolated from the small intestine using curved tip tweezers. Lastly, the femur is extracted by two cuts in the pelvic bone and dislocation of the knee. Harvesting of various other anatomical compartments, including bronchoalveolar lavage (BAL), lungs and lymph nodes as previously described (Li et al., 2017). All organs are placed in ice-cold PBS for further processing.

\section{Preparation of single-cell suspension of various murine organs (Timing: 15 min per mouse)}

1. Spleen tissue is mechanically disrupted using a $100 \mu \mathrm{m}$ cell strainer on a $50 \mathrm{ml}$ tube and the plunger of a $2 \mathrm{ml}$ syringe. During and following processing of the spleen, strainers are flushed with $5 \mathrm{ml}$ of RPMI 1640 Glutamax $^{\mathrm{TM}}$ supplemented with 2\% (vol/vol) FBS (RMPI-2\% FBS) to acquire all cells. Peyer's patches are processed in a similar manner, using a $100 \mu \mathrm{m}$ cell strainer and a Petri dish. Strainers are flushed with maximal $200 \mu \mathrm{l}$ of RMPI-2\% FBS to acquire all cells. CRITICAL: It is important to immediately put the tubes with single cell suspension back on ice or place them in the fridge at $4{ }^{\circ} \mathrm{C}$ after processing.

2. The femur is processed using a mortar and pestle, crushing the bone and acquiring the bone marrow cells in $3 \mathrm{ml}$ of RMPI-2\% FBS. The bone marrow cell suspension is transferred through a $100 \mu \mathrm{m}$ cell strainer on a $50 \mathrm{ml}$ tube to ensure a single cell solution without parts of bone. The bone marrow cell suspension is kept on ice for upcoming procedures.

3. Peritoneal lavage cells are centrifuged at $400 \times g$ for $7 \mathrm{~min}$ at $4{ }^{\circ} \mathrm{C}$ and the supernatant is discarded. Peritoneal lavage cell pellets are resuspended in $1 \mathrm{ml}$ of RMPI-2\% FBS and are kept on ice for upcoming procedures.

4. A cell counting sample is taken from all organs to determine the exact number of cells in each sample. 
CRITICAL: To measure ex vivo basal levels of phosphorylation, cells are kept on ice without any stimulation. Immediately proceed to Step C1.

PAUSE POINT: Cells can be kept at $4{ }^{\circ} \mathrm{C}$ for $1-2 \mathrm{~h}$ before proceeding with the phosphoflow protocol.

B. In vitro stimulation of single-cell suspension (Timing: 30 min-6 h)

1. Stimulation and staining of cells is performed in 96-wells round bottom plates, using $5 \times 10^{5}$ per well $\left(200,000-1,000,000\right.$ cells is technically most optimal). $5 \times 10^{5}$ cells per well are transferred in a volume of $50 \mu \mathrm{l}$ in each well on ice, keeping the cells all time at $4{ }^{\circ} \mathrm{C}$.

2. For stimulation times of less than $1 \mathrm{~h}$, the 96 -wells round bottom plate is placed in a water bath at $37^{\circ} \mathrm{C}$. Make sure only the bottoms of the wells are in contact with the water. For stimulation times longer than $1 \mathrm{~h}$, the stimulus is added while the cells are on ice and subsequently incubated at $37{ }^{\circ} \mathrm{C}$ and $5 \% \mathrm{CO}_{2}$. The optimal stimulation time for phosphotargets in human and murine samples are stated in the original paper (Rip et al., 2020) and Table 2.

CRITICAL: Some phospho-targets in murine B cells, mainly downstream signaling molecules as NF-KB and $A K T / S 6$, are receptive to temperature changes and mechanical stress due to isolation of single cells. Rest these samples at $37^{\circ} \mathrm{C}$, preferably in a $\mathrm{CO}_{2}$ incubator, for $3 \mathrm{~h}$ prior to stimulation. This is critical for optimal detection and sensitivity of the downstream signaling read-outs. The pre-incubation for these targets on frozen PBMCs is not recommendable, as the viability of these cells is lower compared to fresh material.

OPTIONAL: For experiments including in vitro treatment of samples with BCR signaling inhibitors, incubate cell suspensions $3 \mathrm{~h}$ at $37^{\circ} \mathrm{C}$ with BCR signaling for effective pre-treatment. If the signaling target requires resting, pre-treatment can be performed during this resting time.

3. When stimulating cells in a water bath, wait 1-2 min to let the samples reach $37^{\circ} \mathrm{C}$. Add the stimulating agent by pipetting $50 \mu \mathrm{l}$ of stimulus to the wells containing $50 \mu \mathrm{l}$ of sample. The unstimulated control samples are supplemented with $50 \mu \mathrm{RMPI}-2 \%$ FBS as stimulation control. In addition, add $10 \mu \mathrm{l}$ RPMI-2\% FCS containing fixable live/dead viability stain $10 \mathrm{~min}$ prior to fixation.

CRITICAL: As the fixable live/dead viability stain is light sensitive and is not optimal in RPMI medium, prepare this solution freshly and add to the cells within 15 min post preparation.

4. Dilute the eBioscience FoxP3 fixation and permeabilization buffer 1:1 with the supplied diluent. When the stimulation time is over, fix the cells by adding $100 \mu \mathrm{l}$ of the diluted fixation and permeabilization buffer for $10 \mathrm{~min}$ at $37^{\circ} \mathrm{C}$.

CAUTION: This product contains paraformaldehyde (PFA), a toxic and mutagenic product. It should be handled with care and discarded as hazardous waste.

NOTE: The supplied fixation buffer is $4 x$ concentrated and is diluted in the supplied diluent by combining both in equal volume. The diluted fixative solution is added in equal volume the cells to reach the recommended working concentration (50 $\mu \mathrm{l}$ of $4 \times$ fixation buffer $+50 \mu \mathrm{l}$ of diluent to the $100 \mu$ l of cells in RPMI). 
5. After $10 \mathrm{~min}$ of fixation, centrifuge at $400 \times g$ for $3 \min$ at $4{ }^{\circ} \mathrm{C}$. Carefully remove the supernatant.

6. Wash by adding $200 \mu \mathrm{l}$ eBioscience Wash Buffer to all wells and centrifuge at $400 \times g$ for $3 \mathrm{~min}$ at $4{ }^{\circ} \mathrm{C}$. Carefully remove the supernatant afterwards. Perform this step two times. Proceed to Step D1.

CRITICAL: Two times washing is critical in order to remove all fixation and permeabilization buffer.

PAUSE POINT: Proceed directly to staining for flow cytometry or keep the cells in a volume of $200 \mu \mathrm{l}$ of eBioscience Wash Buffer at $4{ }^{\circ} \mathrm{C}$. This storage of cells at $4{ }^{\circ} \mathrm{C}$ is possible up to 5 days, without impacting the quality of the samples.

C. Fixation of single-cell suspensions for ex vivo measurements (Timing: $30 \mathrm{~min}$ )

1. Parallel to stimulated cells, $5 \times 10^{5}$ cells per well are transferred in a 96-wells round bottom plate at a volume of $100 \mu \mathrm{l}$ per well on ice, keeping the cells at $4{ }^{\circ} \mathrm{C}$ at all times.

CRITICAL: This procedure must always be performed at $4{ }^{\circ} \mathrm{C}$, as this is a read-out of ex vivo activation and temperature alterations could be of great influence.

2. Samples are stained with the fixable live/dead viability stain for $10 \mathrm{~min}$ at $4{ }^{\circ} \mathrm{C}$ in the dark prior to fixation.

CRITICAL: As the fixable live/dead viability stain is not optimal in RPMI medium, prepare this solution freshly and add to the cells within 15 min post preparation.

3. Fix cells with $100 \mu \mathrm{l}$ of the diluted fixation and permeabilization buffer for $10 \mathrm{~min}$ at $4{ }^{\circ} \mathrm{C}$.

4. After $10 \mathrm{~min}$ of fixation, centrifuge at $400 \times g$ for $3 \mathrm{~min}$ at $4{ }^{\circ} \mathrm{C}$. Carefully remove the supernatant.

5. Wash by adding $200 \mu \mathrm{l}$ eBioscience Wash Buffer to all wells and centrifuge at $400 \times g$ for $3 \mathrm{~min}$ at $4{ }^{\circ} \mathrm{C}$. Carefully remove the supernatant afterwards. Perform this step two times.

CRITICAL: Two times washing is critical in order to remove all fixation and permeabilization buffer.

PAUSE POINT: Proceed directly to staining for flow cytometry or keep the cells in a volume of $200 \mu \mathrm{l}$ of eBioscience Wash Buffer at $4{ }^{\circ} \mathrm{C}$. This storage of cells at $4{ }^{\circ} \mathrm{C}$ is possible up to 5 days, without impacting the quality of the samples.

D. Flow cytometry procedures (Timing: 1-2 h)

1. After the last wash at Step B6 or Step C5, supernatant is removed and the staining mix can be added. Cells are incubated with $40 \mu \mathrm{l}$ mix to intracellularly stain for cell surface markers such as CD3, B220/CD19, IgD and IgM in eBioscience Wash Buffer. An FcR-blocking agent is added to the staining mix to avoid non-specific binding of the antibodies. Cells are incubated in the dark for 30 min at $4{ }^{\circ} \mathrm{C}$.

CAUTION: Sodium azide is highly toxic and dangerous to the environment. It should be handled with care and discarded as hazardous waste.

CRITICAL: Carefully resuspend the pellet in $40 \mu \mathrm{l}$ mix, ensuring all cells are in suspension. 
NOTE: The staining can also be performed for $15 \mathrm{~min}$ at room temperature $\left(R T, \sim 20^{\circ} \mathrm{C}\right)$ in the dark.

2. Samples are washed by adding $200 \mu \mathrm{l}$ eBioscience Wash Buffer to all wells and centrifuge at $400 \times g$ for $3 \mathrm{~min}$ at $4{ }^{\circ} \mathrm{C}$. Carefully remove the supernatant afterwards.

3. Incubate the samples with $40 \mu \mathrm{l}$ eBioscience Wash Buffer containing the phospho-target antibody of choice for 30 min at RT in the dark.

OPTIONAL: If the phospho-target antibody is already labeled with a conjugate, proceed to Step D6 upon completion of the incubation time.

4. Samples are washed by adding $200 \mu \mathrm{l}$ eBioscience Wash Buffer to all wells and centrifuge at $400 \times g$ for $3 \mathrm{~min}$ at $4{ }^{\circ} \mathrm{C}$. Carefully remove the supernatant afterwards.

5. When the phospho-protein concerns an unconjugated rabbit-derived antibody, incubate with a donkey anti-rabbit PE-conjugated antibody for $15 \mathrm{~min}$ at RT in the dark.

6. Samples are washed with MACS Buffer (0.5\% BSA and 2 mM EDTA in PBS) and centrifuged at $400 \times g$ for $3 \mathrm{~min}$ at $4{ }^{\circ} \mathrm{C}$. Remove the supernatant and resuspended in $50 \mu \mathrm{l}$ MACS buffer. Samples are transferred into insert tubes and measured using a flow cytometer within 1 day.

7. Prior to measuring, calibrate the LSR-II by compensating for all conjugates that are used within the phospho-staining. Preferably use the same antibodies as used in the staining mix and add those to UltraComp eBeads (Invitrogen) according to manufacturer instructions to calibrate the flow cytometer.

8. Acquire a sufficient number of cells to perform $B$ cell subpopulation analysis. This would imply that acquiring between $20,000-50,000$ B cells per sample would be sufficient.

CRITICAL: Due to the fixation and permeabilization protocol, the cell size will have decreased compared with non-fixed cells. Increase the voltage of the forward-scatter area (FSC-A) accordingly.

9. Analysis is performed using FlowJo v9 or v10 software.

\section{Data analysis}

In this protocol manuscript, we include targets described in the original paper (Rip et al., 2020) and provide directions on the analyses of several additional phospho-targets that we recently established.

For each target, it is crucial to first find the best stimulus and identify the most optimal time of stimulation. Table 2 provides directions on the optimal stimulation time for BCR signaling molecules mentioned in the original paper (Rip et al., 2020) and additional phospho-targets in mice and men. During optimization of the subset and phospho-target staining procedure, all antibodies should be validated by including isotype and fluorescence minus one (FMO) controls, thereby verifying the signal intensities. Following acquisition of the cells by the flow cytometer, compensation can be checked and adjusted when necessary using the FlowJo 10 Software program. 
As a data analysis example, Figure 1 provides an overview of the phosphorylation status analysis for various BCR signaling molecules in B cells from human PBMC fractions, either unstimulated or stimulated by anti-IgM $F\left(a b^{\prime}\right)_{2}$ fragments or recombinant $\mathrm{CD} 40 \mathrm{~L}$. Prior to gating $\mathrm{B}$ cell subpopulations, we first selected for live, single lymphocytes followed by the identification of $B$ cells with the pan-B cell marker CD19 (Figure 1A). We included CD3 in the staining to enable accurate

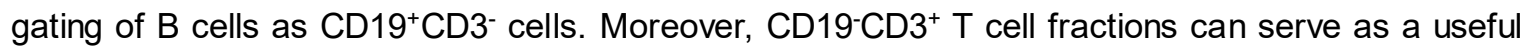
negative control for the analysis of phosphorylation of BCR signaling molecules as $T$ cells are not responsive to anti-IgM stimulation. Within live $\mathrm{CD} 19^{+} \mathrm{B}$ cells, the populations of transitional $\mathrm{B}$ cells and plasmablasts were identified as $\mathrm{CD} 27^{-} \mathrm{CD} 38^{+}$and $\mathrm{CD} 27^{+} \mathrm{CD} 38^{+}$cells, respectively. $\mathrm{B}$ cells with low CD38 expression were subsequently divided into naive $\mathrm{CD}^{-} 7^{-} \lg \mathrm{I}^{+} \mathrm{B}$ cells and $\mathrm{CD}^{-1} 7^{+} \mathrm{IgD} \mathrm{g}^{-}$ memory B cells (Figure 1A).

As a next step, phosphorylation of BCR signaling molecules was analyzed in gated B cell subpopulations. For example, we gated on CD27-lgD+ naive B cells and analyzed PLCY2 (Y759) phosphorylation. For this analysis, next to FMO or isotype controls, gated $\mathrm{T}$ cells served as a negative staining control, because PLCY2 is not expressed in T cells. The histogram overlays in Figure 1B show that the $\mathrm{pPLC}$ 2 fluorescence signals of naive $B$ cells were strongly increased upon anti-IgM stimulation, compared with unstimulated naive $B$ cells. It is of note that unstimulated cells often show low but detectable ex vivo phosphorylation of various BCR signaling proteins. Phosphorylation signals were quantified by geometric mean fluorescence intensity ( $g \mathrm{MFI}$ ) values, because we observed stimulation-induced intensity shifts of a single peak in the case of pPLCY2 (Figure 1B). In contrast, phosphorylation is quantified by calculating proportions of positive cells when a bimodal distribution is observed (for example for phosphorylation of ribosomal protein S6 (Figure 1C). We usually also include a vertical line for reference that is set either (i) at the peak of the counts of the unstimulated control, when stimulation results in an intensity shift of a single peak; or (ii) to indicate background signals, when stimulation increased the numbers of positive cells in a bimodal staining distribution (as in pS6).

Additional examples include the analysis in total CD19 $\mathrm{B}$ cells fractions of phosphorylation of CD79a and ribosomal protein S6, a downstream target of the AKT signaling pathway (Figure 1C). Finally, we show histogram overlays of phosphorylation targets that were not previously described in Rip et al. (2020), including the activating Y418 (in mouse B cells: Y424) and inhibitory Y507 of Src-family kinases, PI3K p85 subunit (Y458) and the Src homology region 2 domain-containing phosphatase-1 (SHP-1; Y564) (Figure 1D). 
A

A live cells

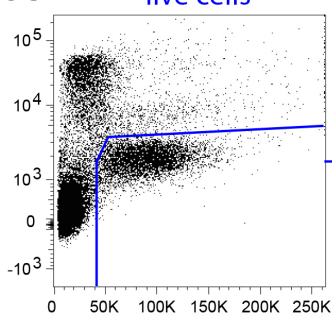

L/D
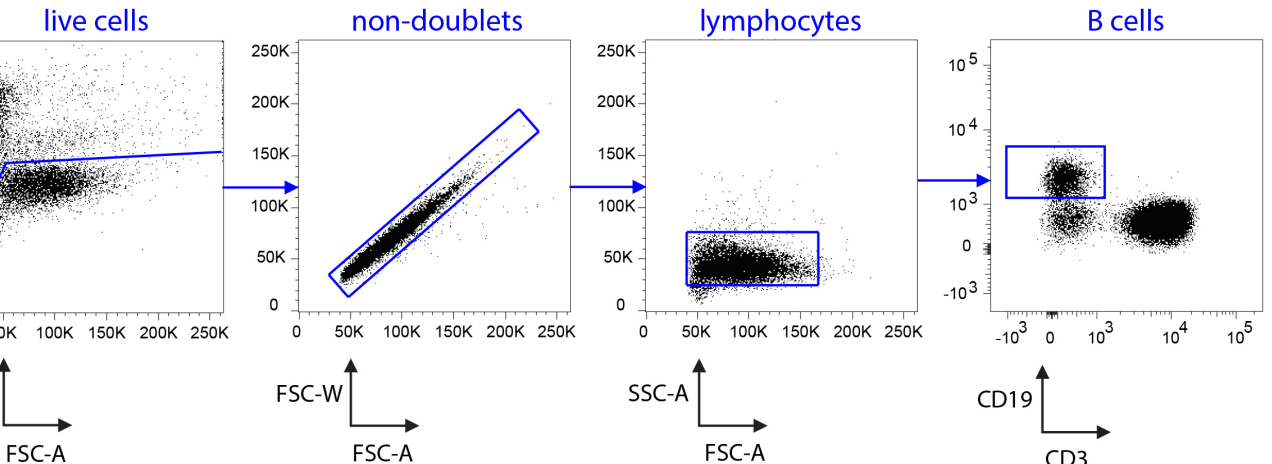

FSC-W $\underset{\text { FSC-A }}{\longrightarrow}$

SSC-A $\underset{\text { FSC-A }}{\longrightarrow}$

$\mathrm{CD} 19{\underset{\mathrm{CD} 3}{\longrightarrow}}_{\longrightarrow}^{\longrightarrow}$
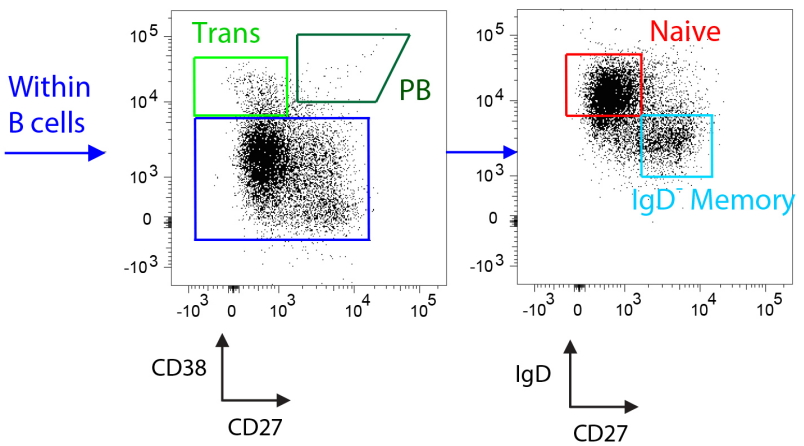

B

C

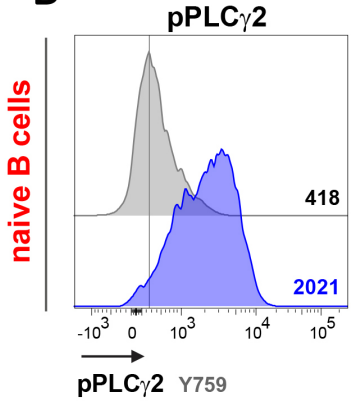

$\Lambda_{\text {unstimulated }}$

$\Lambda$ anti-lgm

$\Lambda_{\mathrm{rhCD} 40 \mathrm{~L}+}$ rhIL-4

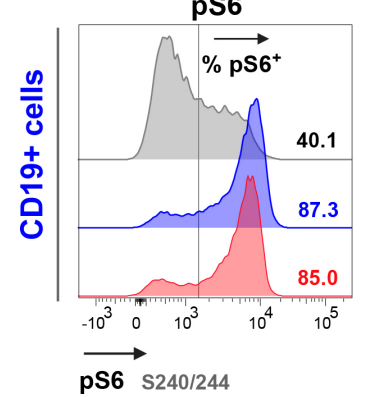

pCD79a

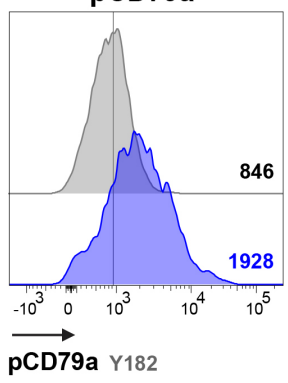

D

PSRC - Y507

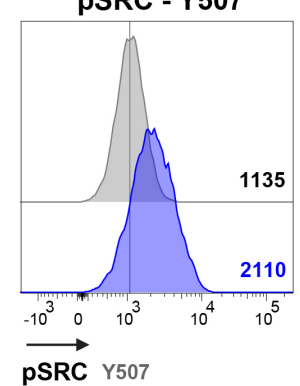

pPI3K p85

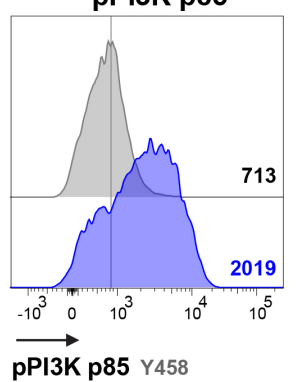

pSHP-1

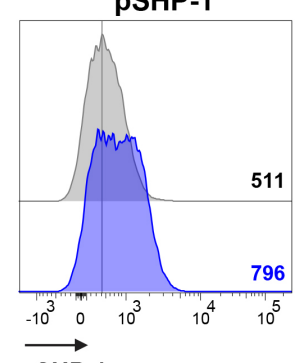

pSHP-1 Y564

Figure 1. Phosphorylation of BCR molecules in PBMC-derived B cells. A. Gating strategy for live single lymphocytes from the peripheral blood mononuclear cell (PBMC) fraction. Within lymphocytes, we gated for $\mathrm{CD} 19^{+}$cells $\left(\mathrm{CD} 19^{+} \mathrm{CD} 3^{-}\right)$. After exclusion of transitional B cells (Trans) and plasmablasts (PB), we gated for naive $B$ cells (CD19 $\left.{ }^{+} \mathrm{CD} 38^{-} \lg \mathrm{D}^{+} \mathrm{CD} 27^{-}\right)$and IgDnegative memory $B$ cells $\left(C D 19^{+} C D 38-\lg D^{-} C D 27^{+}\right)$. B. Histogram overlay for pPLCY2 in naive $B$ cells after 5 min of anti-IgM stimulation. C. Histogram overlay for pS6 after 30 min of anti-IgM or recombinant human CD40 ligand (CD40L) and IL-4 stimulation, and for pCD79a after 1 min of 
anti-IgM in total CD19+ $B$ cells. D. Histogram overlays of total CD19+ $B$ cells for $p S R C-Y 418$ after 1 min of anti-IgM stimulation and for pSRC-Y507, pPI3K p85 and pSHP-1 after 3 min of anti-IgM stimulation. Vertical lines in histograms are set on unstimulated controls as reference for stimulation, whereby the quantification by geometric mean fluorescence intensity $(g M F I)$ is indicated. Only for ribosomal protein S6, which showed a bimodal distribution, phosphorylation is quantified by calculating proportions of positive cells (C). Graphs represent representative histograms of 2-10 individual experiments, each with 2-20 healthy donors per group.

In Figure 2 we present a parallel phospho-analyses on some previously validated (Rip et al., 2020) and novel targets for murine $B$ cells. We selected live splenic $B$ cells by gating on live B220 ${ }^{+}$cells and subsequently for naive $B$ cells by $\lg D$ and $\lg M$ receptor expression (Figure $2 A$ ). Within naive $B$ cells, we gated on follicular and marginal zone (MZ) B cells, using CD21 and CD23 (Figure 2A). Phosphorylation of PLCY2 in follicular B cells showed about a 2.5-fold increase upon stimulation with anti-IgM (Figure 2B). Likewise, robust phosphorylation of CD79a following anti-IgM stimulation and of S6 following anti-IgM, anti-CD40 or lipopolysaccharide (LPS) stimulation was detected in naive $B$ cells (Figure $2 \mathrm{C}$ ). Additional $\mathrm{BCR}$ targets also displayed responsiveness following anti-lgM stimulation, with an optimal signal at 5 min for pSrc kinases (for both Y424 and Y507) and 1 min for pPI3K p85 and pSHP-1 (Figure 2D). 

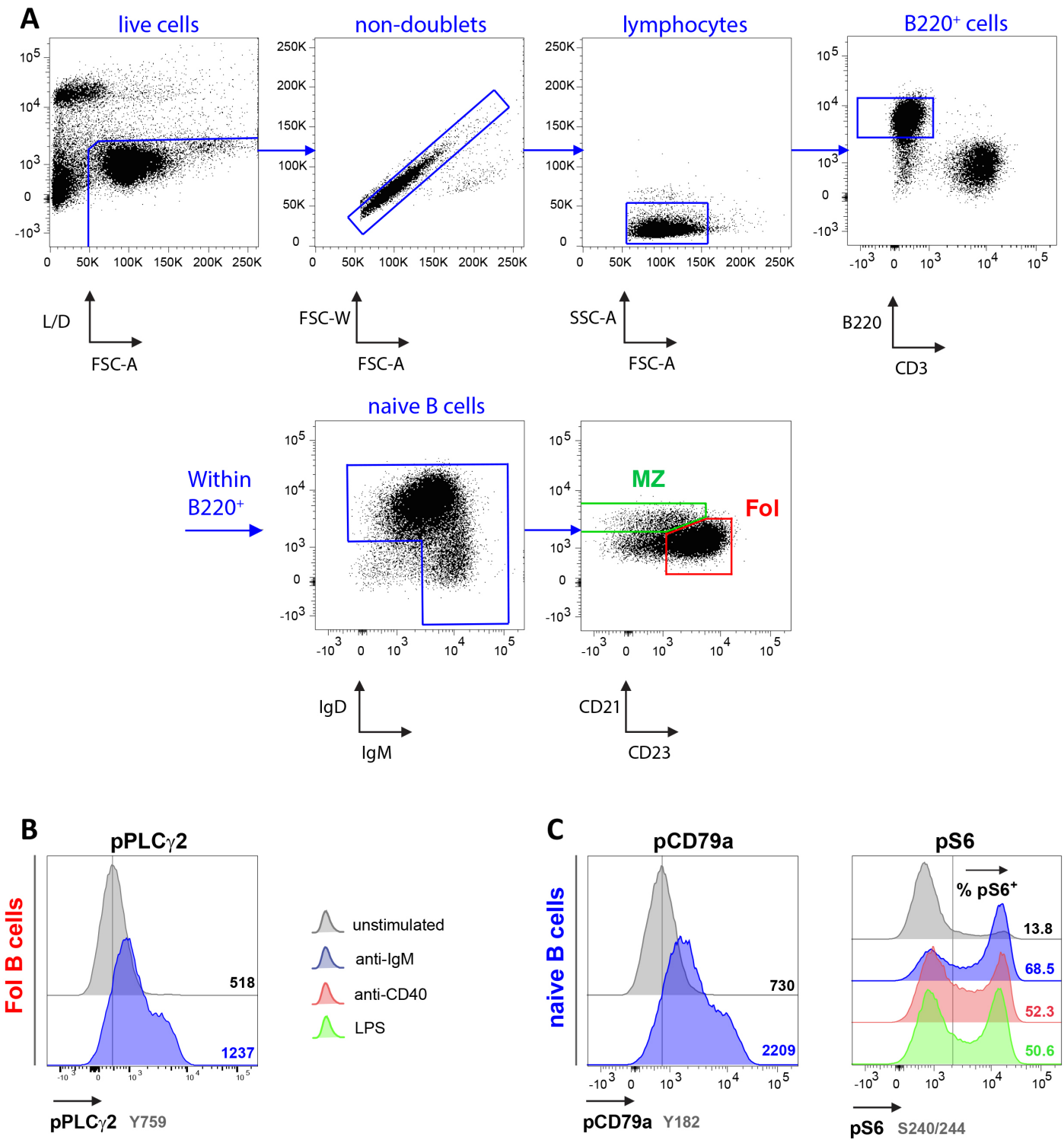

$\Lambda$ unstimulated

$\Lambda_{\text {anti-IgM }}$

$\bigwedge$ anti-CD40

$\bigwedge$ LPS

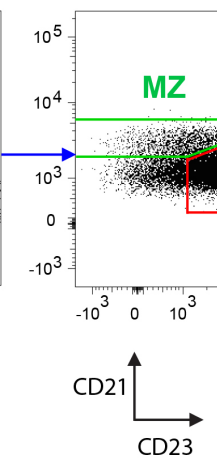

C 2 Y 75
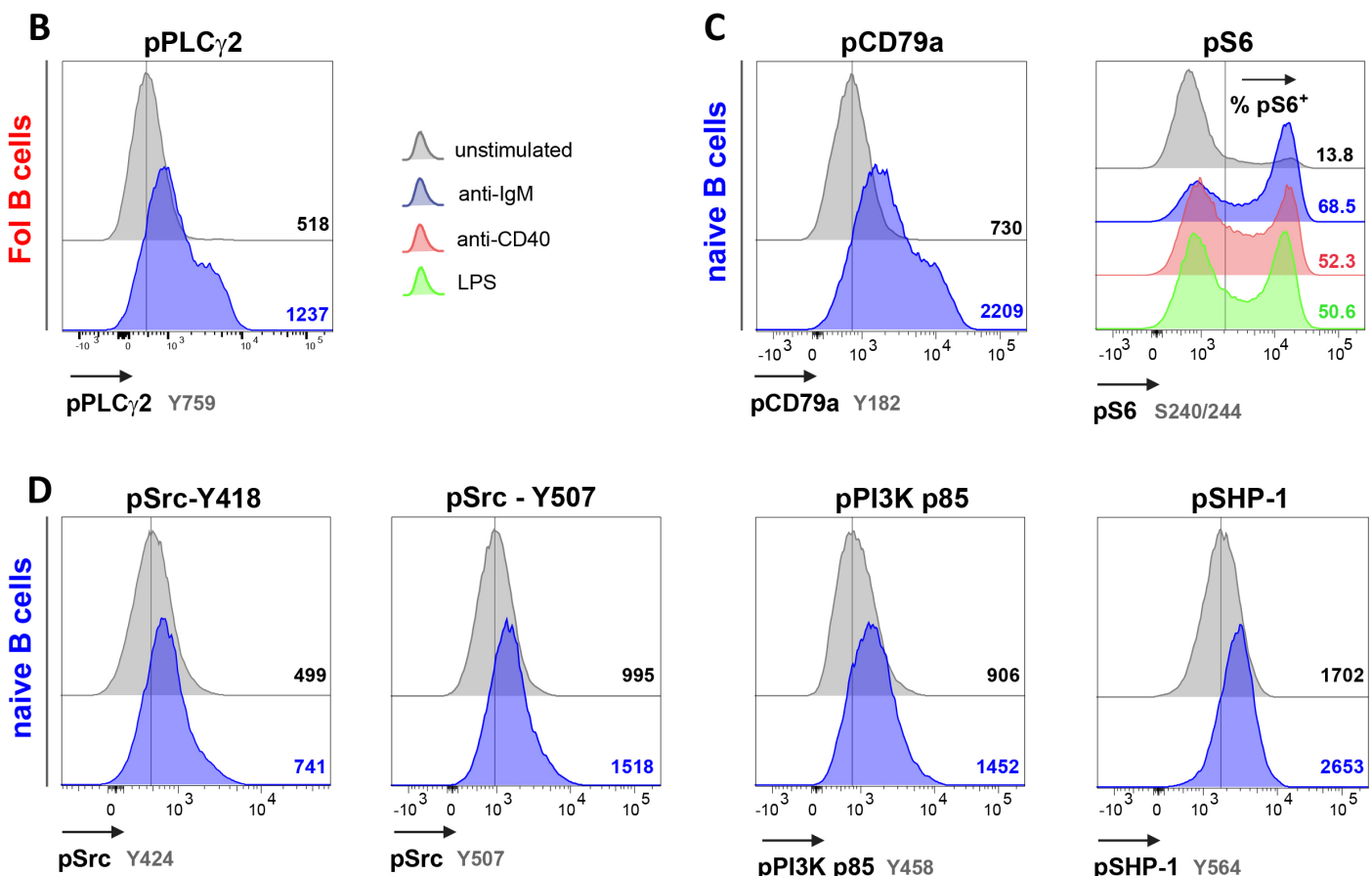

Figure 2. Phosphorylation of $B C R$ molecules in splenic murine $B$ cells. A.Gating strategy for live, single splenic lymphocytes. Within lymphocytes, we gated for splenic $\mathrm{B}^{2} 20^{+}$cells

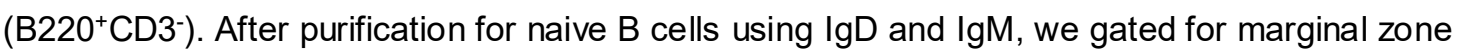
(MZ) B cells $\left(B 220^{+} \mathrm{CD} 21^{+} \mathrm{CD} 23^{-}\right)$and follicular (Fol) B cells $\left(B 220^{+} \mathrm{CD} 21-\mathrm{CD} 23^{+}\right)$. B. Histogram overlay for pPLCY2 after 5 min of anti-IgM stimulation in Fol B cells. C. Histogram overlays for pCD79 after $5 \mathrm{~min}$ of anti-IgM stimulation or pS6 after $3 \mathrm{~h}$ of anti-IgM, anti-CD40 or 
Lipopolysaccharide (LPS) stimulation. D. Histogram overlays of total naive B cells for pSrc-Y424 and pSrc-pY507 after 5 min and for pPI3K p85 and SHP-1 after 1 min of anti-lgM stimulation. Vertical lines in histograms are set on unstimulated controls as reference for stimulation, whereby the quantification by geometric mean fluorescence intensity $(g M F I)$ is indicated. Only for ribosomal protein $\mathrm{S6}$, which showed a bimodal distribution, phosphorylation is quantified by calculating proportions of positive cells (C). Graphs represent representative histograms of $>3$ individual experiments, each with 5 mice per group; wild-type mice were 8-12 weeks old.

\section{$\underline{\text { Notes }}$}

1. Timing for phosphorylation of other signaling proteins was presented in our original paper (Figures 1-3 and an schematic overview in Figure S2) (Rip et al., 2020).

2. It is not required to perform multiple washing steps, since we did not find differences in the quality of the staining between procedures with single or multiple washing steps. Single washing steps are therefore sufficient, unless otherwise indicated within the methods section.

3. The phosphoflow protocol was developed and validated for RPMI1640 medium. We did not investigate effects of other types of medium or supplements such as HEPES or 2-Mercaptoethanol.

4. Dilutions and timing of the previously validated and additional targets shown in the Data analysis are included in Table 2. Note that both mAb dilution and timing for the phospho-antibody can vary between human and murine samples.

5. Phosphorylation of STAT protein and read-out for the NF-KB signaling pathway should be performed using other protocols, as mentioned in our original paper (Figures 2-3 and Figure S1) (Rip et al., 2020).

6. In downstream signaling pathways in freshly acquired murine B cells are receptive to temperature changes and mechanical stress due to isolation of single cells. Rest these samples at $37^{\circ} \mathrm{C}$ prior to stimulation, preferably in an $\mathrm{CO}_{2}$ incubator. We recommend to rest the samples $3 \mathrm{~h}$, as is critical for optimal detection and sensitivity of the downstream signaling read-outs.

7. The pre-incubation for downstream signaling is not recommended on frozen PBMCs, as this strongly affects viability. We did not encounter this viability issue on frozen splenic suspensions derived from murine tissue.

\section{$\underline{\text { Recipes }}$}

Solutions are not filtered; media, sera and buffers are sterile, fetal bovine serum (FBS) is heatinactivated for $1 \mathrm{~h}$ at $56^{\circ} \mathrm{C}$ prior to use.

1. Freezing medium

$80 \%$ Fetal Bovine Serum

$20 \%$ Dimethyl sulfoxide 
2. RPMI-2\% FCS

RMPI 1640

$2 \%$ Fetal Bovine Serum

3. RPMI-5\% FBS

RPMI 1640

$5 \%$ Fetal Bovine Serum

4. MACS Buffer

Phosphate-buffered saline

$0.5 \%$ Bovine Serum Albumin

$2 \mathrm{mM}$ Ethylenediaminetetraacetic acid solution

\section{Acknowledgments}

These studies were partially supported by the Dutch Cancer Society (KWF grant 2014-6564) and Target-to-B, both awarded to R.W. Hendriks, as well as an unrestricted grant from AcertaPharma B.V. Oss.

We would like to thank Allard Kaptein (AcertaPharma B.V., Oss), Stefan Neys and Marjolein de Bruijn (Erasmus MC Rotterdam) and the EDC Erasmus MC animal facility for their great technical assistance.

\section{Author Contributions}

JR designed the research, performed experiments, analyzed the data, and wrote the manuscript. $\mathrm{OC}$ and $\mathrm{RH}$ contributed to the research design and the writing of the manuscript and supervised the study. All co-authors approved the final manuscript.

\section{Competing interests}

The authors declare to have no financial conflicts of interest.

\section{Ethics}

PBMCs were obtained from healthy volunteers (Rotterdam Centrum, the Netherlands). Experimental procedures were approved by the ethics committee of the Erasmus MC.

Prior to animal experiments, all experimental protocols were reviewed and approved by the Erasmus MC Committee of animal experiments (DEC) and the central committee for animal experiments (CCD) with approval ID AVD1010020173764. CCD approval is valid until the $1^{\text {st }}$ of June 2023. 


\section{$\underline{\text { References }}$}

1. Bajpai, U. D., Zhang, K., Teutsch, M., Sen, R. and Wortis, H. H. (2000). Bruton's tyrosine kinase links the B cell receptor to nuclear factor kappaB activation. J Exp Med 191(10): 1735-1744.

2. Craxton, A., Jiang, A., Kurosaki, T. and Clark, E. A. (1999). Syk and Bruton's tyrosine kinase are required for $B$ cell antigen receptor-mediated activation of the kinase Akt. $J$ Biol Chem 274(43): 30644-30650.

3. Fluckiger, A. C., Li, Z., Kato, R. M., Wahl, M. I., Ochs, H. D., Longnecker, R., Kinet, J. P., Witte, O. N., Scharenberg, A. M. and Rawlings, D. J. (1998). Btk/Tec kinases regulate sustained increases in intracellular $\mathrm{Ca}^{2+}$ following B-cell receptor activation. EMBO J 17(7): 1973-1985.

4. Franks, S. E. and Cambier, J. C. (2018). Putting on the Brakes: Regulatory Kinases and Phosphatases Maintaining B Cell Anergy. Front Immunol 9: 665.

5. Jiang, A., Craxton, A., Kurosaki, T. and Clark, E. A. (1998). Different protein tyrosine kinases are required for $B$ cell antigen receptor-mediated activation of extracellular signal-regulated kinase, c-Jun NH2-terminal kinase 1, and p38 mitogen-activated protein kinase. J Exp Med 188(7): 1297-1306.

6. Kil, L. P., de Bruijn, M. J., van Nimwegen, M., Corneth, O. B., van Hamburg, J. P., Dingjan, G. M., Thaiss, F., Rimmelzwaan, G. F., Elewaut, D., Delsing, D., van Loo, P. F. and Hendriks, R. W. (2012). Btk levels set the threshold for B-cell activation and negative selection of autoreactive B cells in mice. Blood 119(16): 3744-3756.

7. Li, B. W. S., Beerens, D., Brem, M. D. and Hendriks, R. W. (2017). Characterization of Group 2 Innate Lymphoid Cells in Allergic Airway Inflammation Models in the Mouse. Methods Mol Biol 1559: 169-183.

8. Martensson, I. L., Almqvist, N., Grimsholm, O. and Bernardi, A. I. (2010). The pre-B cell receptor checkpoint. FEBS Lett 584(12): 2572-2579.

9. Nishizumi, H., Taniuchi, I., Yamanashi, Y., Kitamura, D., Ilic, D., Mori, S., Watanabe, T. and Yamamoto, T. (1995). Impaired proliferation of peripheral B cells and indication of autoimmune disease in lyn-deficient mice. Immunity 3(5): 549-560.

10. Pieper, K., Grimbacher, B. and Eibel, H. (2013). B-cell biology and development. J Allergy Clin Immunol 131(4): 959-971.

11. Rip, J., de Bruijn, M. J. W., Kaptein, A., Hendriks, R. W. and Corneth, O. B. J. (2020). Phosphoflow protocol for signaling studies in human and murine B cell subpopulations. $J$ Immunol 204(10): 2852-2863.

12. Rip, J., Van Der Ploeg, E. K., Hendriks, R. W. and Corneth, O. B. J. (2018). The role of bruton's tyrosine kinase in immune cell signaling and systemic autoimmunity. Crit Rev Immunol 38(1): $17-62$. 
13. Saito, K., Scharenberg, A. M. and Kinet, J. P. (2001). Interaction between the Btk PH domain and phosphatidylinositol-3,4,5-trisphosphate directly regulates Btk. J Biol Chem 276(19): 16201-16206.

14. Tonegawa, S. (1983). Somatic generation of antibody diversity. Nature 302(5909): 575-581.

15. Wang, D., Feng, J., Wen, R., Marine, J. C., Sangster, M. Y., Parganas, E., Hoffmeyer, A., Jackson, C. W., Cleveland, J. L., Murray, P. J. and Ihle, J. N. (2000). Phospholipase Cgamma2 is essential in the functions of B cell and several Fc receptors. Immunity 13(1): 25-35. 